\title{
Lymph Node Dissection Was Not Performed
}

National Cancer Institute

\section{Source}

National Cancer Institute. Lymph Node Dissection Was Not Performed. NCI Thesaurus.

Code C160398.

An indication that lymph node dissection was not performed during the study. 